\title{
UN MUNDO LICENCIADO O LICENCIOSO: EL LICENCIAMIENTO Y LA PROTECCIÓN ADMINISTRATIVA DEL AMBIENTE EN COLOMBIA*
}

DOI: http://dx.doi.org/10.17981/juridcuc.11.1.2015.8

Recibido: 30 de Abril de 2015 / Revisado: 14 de Julio de 2015 / Aceptado: 17 de Julio de 2015

\section{Juan Fernando Romero Tobón ${ }^{* *}$ \\ Universidad Nacional de Colombia}

Puede citar el presente artículo así: / To reference this article:

Romero, J. (2015). Un mundo licenciado o licencioso: el licenciamiento y la protección administrativa del ambiente en Colombia. Jurídicas CUC, 11(1), 183-208. doi: http://dx.doi.org/10.17981/juridcuc.11.1.2015.8

\section{Resumen}

Este texto pretende demostrar que el proceso de licenciamiento no está enmarcado en la real defensa del ambiente. Obedece a un trámite que suscita, en quienes lo gestionan, la pulsión de finiquitarlo y conceder el permiso sin un contenido sustancial ni una orientación destinada a revisar integralmente las consecuencias. La participación ciudadana y la consulta previa son apenas escollos que se traducen como una oposición entre las "mayorías" que quieren el desarrollo del país, la concepción econeoliberal o ecocapitalista en la que se afirma preservar el ambiente y unas "minorías" que se opondrían al mismo. En general, el proceso no responde a los cánones de justicia ambiental ni de afianzamiento frente a los daños que se pueden producir y, en cierta manera, conduce a plantear un estado inconstitucional de cosas.

\section{Palabras clave:}

Ambiente, protección administrativa, licencias ambientales, participación ciudadana, seguro ecológico

\footnotetext{
* Artículo de reflexión realizado con recursos propios del autor. Especial agradecimiento a los compañeros Manolo Granda y Crystian Hernández.

** Abogado-Antropólogo-Poeta, Especializado en Derecho Económico, Magíster en Derecho Constitucional, Grupo de Investigación Constitucionalismo Comparado. Correo electrónico: jfromerot@hotmail.com
} 


\section{A LICENSING OR LICENSED WORLD: LICENSING AND THE ADMINISTRATIVE PROTECTION OF THE ENVIRONMENT IN COLOMBIA}

\section{Abstract}

This paper aims at proving that the licensing procedure is not framed within a real environmental protection. This procedure prompts its managers to terminate it within a short period of time and to grant the permission lacking substantial content and a thorough evaluation of its consequences. Citizen participation and prior consent of indigenous people are obstacles which are perceived as opposition among, on the one hand, the 'majorities' pursuing the country's development, the eco-neoliberal or eco-capitalist ideology whose alleged purpose is to preserve the environment, and on the other hand, the 'minorities' who are against this. Generally speaking, the procedure does not follow the regulations of the environmental law and is exempted from liability given any foreseeable damages. Somehow, it leads to an unconstitutional situation.

\section{Keywords:}

Environment, Administrative Protection, Environmental Licensing, Citizen Participation, Ecological Insurance. 
-Yo - dijo aún - tengo una flor a la que riego todos los días; poseo tres volcanes a los que deshollino todas las semanas, pues también me ocupo del que está extinguido; nunca se sabe lo que puede ocurrir. Es útil, pues, para mis volcanes y para mi flor que yo las posea. Pero tú, tú no eres nada útil para las estrellas [...] (Saint-Exupéry, 1994)

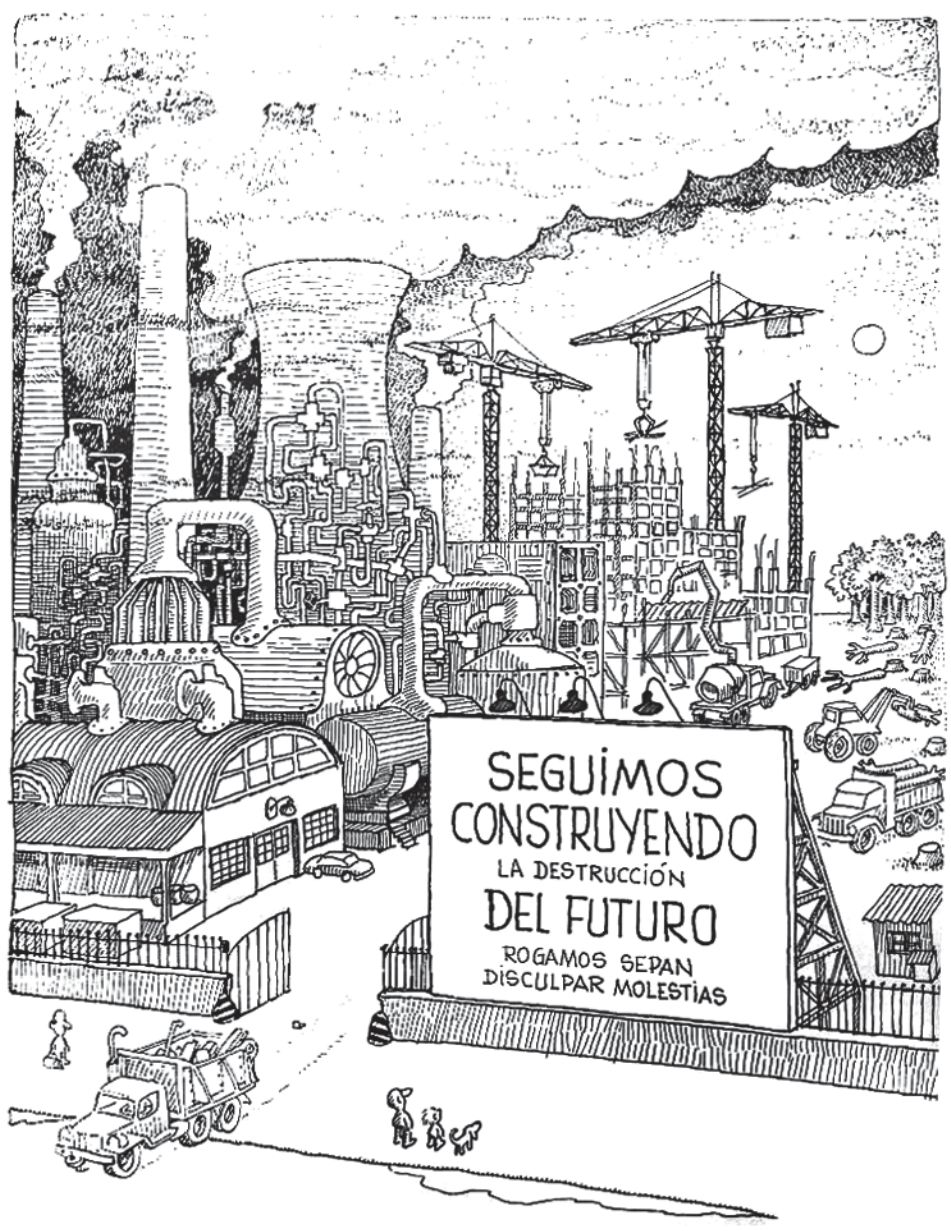

Fuente: Quino, Disponible en:

hhttp://pbs.twimg.com/media/A_FHq11CIAApSA3.jpg:large (Consultado el 12 de noviembre de 2014) 


\section{PRESENTACIÓN}

En este artículo se examinan los mecanismos de protección administrativa del ambiente, especialmente aquél por excelencia representado en la licencia ambiental y todo lo que conlleva el proceso de licenciamiento como una actuación compleja para acceder al mismo, las múltiples fases y etapas que comporta, la participación ciudadana y el afianzamiento por los eventuales daños que se puedan producir, tema que adquiere protagonismo por la reciente expedición del Decreto 2041 (2014). La institucionalidad debería estar destinada a materializarla y evitar la paulatina degradación del ambiente y de los derechos de las personas y de los demás seres vivos, así como la explotación desmedida por quienes perciben a la tierra como una fuente ilimitada de extracción a la que deben serle arrancados sus secretos, aún bajo tortura. En este sentido, es muy diciente que en el Plan Nacional de Desarrollo 2010-2014, adoptado mediante la Ley 1450 (2011) y ad portas de expirar, se aluda a las locomotoras productivas, un símbolo que además de paradójico (Colombia no cuenta con algo que se pueda denominar red ferroviaria), remite a la fase inicial del capitalismo depredador, pues significa pasar por encima de todo lo que se oponga al "desarrollo", y que, además, esta clase de normas sean el pretexto para modificar la Ley 99 de 1993 (Sentencia C-670, 2014).

Para analizar tal protección y el actual propósito estatal de explotación minera, se ha acudido a los planteamientos que surgen de la justicia ambiental y que se nutren de las tesis biocentristas. Frente a la respuesta de desarrollo sostenible antropocentrista, existe la que pretende rescatar la tierra como un sujeto de derechos privilegiado, una madre que debería ser respetada como tal y a la que se le debe reciprocidad (Zaffaroni, 2011, p. 112). A nivel latinoamericano, una propuesta de un nuevo centro, una nueva escala y una nueva forma de expresión (Santos, 2003) se ha producido en países como Bolivia y Ecuador ${ }^{1}$ a través de las transformaciones ocurridas desde mediados de la década

\footnotetext{
${ }^{1}$ Tanto en la Constitución ecuatoriana como en la boliviana la tierra deja de ser un objeto y adquiere una dimensión vital. En el caso ecuatoriano, además de la enunciación de derechos (arts. 72 y 73 C.P.E), se plantea su exigibilidad judicial (art. 11.). En la Constitución Boliviana (art. $8^{\circ}$ ), cuando se alude a los principios éticos, se incorpora los de suma qamaña (vivir bien), ñandereko (vida armoniosa), teko kavi (vida buena), ivi marei (tierra sin mal) y qhapaj ñan (camino o vida noble), también presente en la constitución ecuatoriana (capítulo II del título de derechos).
} 
pasada (Marquardt, 2011, p. 272). Es una mirada que, adicionalmente, propone un acento global planetario, escenario en donde sólo puede tener eficacia (Arnaud, 2000, p. 17), y en donde la noción de que el planeta es un navío en el océano del universo puede dar una idea del alcance del cambio de paradigma. A ello se agrega la dimensión de ser vivo que impide ejercer el típico derecho de propiedad. Para el presente análisis, resultan entonces reveladoras las tesis de Martínez Alier (1994), sobre la responsabilidad de la grave afectación al ambiente y el planteamiento biocentrista que se recoge en el pensamiento indígena del buen vivir o Sumak Kawsay (Houtart, 2011). Se acude, igualmente, a la crítica realizada por la profesora Shiva (Shiva, 2001, p. 182) en relación con la mercantilización de la vida y, sin duda y en el campo de la responsabilidad por el impacto ambiental, a lo señalado por Jonas (1995), o responsabilidad hercúlea que es la única que puede dar razones de los efectos para las generaciones futuras y para lo no humano, y con ello, la pirámide de prioridades a la que alude Attfield (2010). Obviamente, esta clase de accesos al ambiente, que son bastante agresivos, tienen relación con la huella ambiental (Mesa, 2010). Así mismo, deberían estar rodeados de una participación deliberativa, previa, consciente, informada y suficiente para que sea efectiva y dialéctica y no solamente formal (Melo, 2009). Con todo lo anterior, no se trata, por lo tanto, de impedir el acceso al ambiente por parte de los seres humanos sino de problematizar las formas de acceso que son excluyentes y predatorias y, por ende, revisar el actual esquema de licenciamiento frente al planteamiento de justicia ambiental.

\section{La protección administrativa del ambiente y el entorno constitucional}

La Constitución de 1991 ha sido caracterizada como una constitución ecológica por parte de la propia Corte Constitucional (Sentencia C-283, 2014). En desarrollo de lo anterior, ese ordenamiento plantea una serie de límites al acceso al ambiente y, derivado de ello, elementos e instancias de protección.

A este respecto, cabe indicar, en primer lugar, que si bien el derecho a un ambiente sano estaría en el renglón de los denominados derechos colectivos y del ambiente (C.P. Capítulo 3, Título II), no significa que 
tenga menor entidad frente a los derechos de primera y segunda "generación" como se pretendió en algún momento. Esta tesis fue tempranamente enfrentada por la Alta Corporación (Sentencia T-406, 1992) y en una decisión reciente se refrenda la igualdad entre derechos (Sentencia C-313, 2014) y lo ficticio de la jerarquización y la prevalencia de los tratados que reconocen derechos humanos ratificados por Colombia (C.P. Art. 93).

De otro lado, como principios fundamentales del Estado que guían su actuar en todos los niveles, están tanto el reconocimiento como la protección de la diversidad étnica y cultural (C.P. Art. 7) y de las riquezas culturales y naturales ${ }^{2}$ (C.P. Art. 8). A su turno, dentro de la relación del ambiente con otros derechos, la Constitución destaca especialmente tres: la atención en salud y el saneamiento ambiental, la educación destinada a la protección del ambiente y la propiedad. El tercero (C.P. Art. 58) es el eje del sistema de acumulación. Como norma vértice, supondría una extensión ilimitada: todo es apropiable o es, o debe ser, de alguien dentro de la tesis de asignación de derechos que retoma la visión de Hardin (Hardin, 1995, en contra, Negri \& Hardt, 2011). Afirmar, entonces, que a la propiedad le subyace una función ecológica (y no ambiental) genera, sin duda, una primera tensión valorativa pues, a juzgar por lo que ha ocurrido con la función social de la propiedad, incorporada entre nosotros a través del Acto Legislativo 1 de 1936, en un país donde la concentración de la propiedad de la tierra en Colombia es una de las más graves del mundo (Ibañez \& Muñoz, 2010; Reyes, 2009; Piccoli, 2008), la propiedad subordina cualquier esfuerzo social y, ahora, ambiental y no a la inversa. Si es así, la autoridad administrativa no afectaría esa noción esencial y excluyente que, en términos de Proudhon, es un robo y, en sí misma, una negación de derechos como la vida y la igualdad. Señala este autor que la tierra "es una cosa común, en consecuencia no susceptible de apropiación” (Proudhon, 1996, p. 134). Así mismo, es curioso que en el artículo 333 constitucional no se indique que la empresa tiene una función ambiental como sí se indica que tiene una función social, pero ello revela ciertos sentidos subyacentes

\footnotetext{
${ }^{2}$ Aunque tales normas abren una puerta de garantismo ambiental, el concepto de riqueza natural tiene una connotación de valor capitalista sin perjuicio de que en el artículo 63 se afirme que están por fuera del mercado (son inembargables, imprescriptibles e inalienables).
} 
al ámbito de protección. Se alude, sin embargo, al límite de la libertad económica por la exigencia de permisos y requisitos que se prevean en la ley, entre las que estarían las licencias.

Ya en el plano de lo específicamente ambiental, el artículo 79 establece la universalidad como elemento del derecho a un ambiente sano y, en concordancia con esa declaración, defiere al legislador la garantía de participación de la comunidad en las decisiones que puedan afectarla (C.P. Art. 1, igualmente). Dicha norma contempla, además, tres ámbitos de protección, a saber, la diversidad e integridad del ambiente, la conservación de áreas de especial importancia "ecológica" y el fomento de la educación. Por su parte, el artículo 80 contiene tres deberes concretos para el Estado:

- El deber de planificación del manejo y aprovechamiento de los "recursos naturales" (no alude a la planificación ambiental como un todo sino acude a una visión sectorial de recurso) con las finalidades, algunas de ellas opuestas, de garantizar el desarrollo sostenible, conservar, restaurar y restituir. En la planeación y la formulación del Plan Nacional de Desarrollo (C.P. Art. 339) se indica que debe contener orientaciones generales de la política ambiental, en el cual participa el Consejo Nacional de Planeación con representación de los sectores "ecológicos" (C.P. Art. 340)

- El deber de prevención y control (en esencia debería tratarse del desarrollo, entre otros, del principio de precaución), de imposición de sanciones y de exigir reparación de daños (principio de responsabilidad). En este plano, la labor de la autoridad administrativa es trascendental pues es precisamente la que puede dimensionar estos aspectos mediante las facultades preventivas (límites o prohibiciones de acceso al ambiente) o sancionatorias.

- El deber de cooperación con naciones fronterizas (en concordancia con los arts. 226 y 289), tema que, derivado del plan Colombia (ofensiva sur) y la guerra contra el narcotráfico, ha suscitado intervencionismo, choques y conflictos (Castro, 2014) más que cooperación ${ }^{3}$.

\footnotetext{
${ }^{3}$ Las tesis de corte imperialista de persecución en caliente, ataque preventivo y extraterritorialidad han generado profundos distanciamientos entre los países, específicamente cuando Venezuela (1998) y Ecuador (2006) dieron un giro hacia otras formas de organización social, económica, política y cultural.
} 
En su pequeña dimensión, el ciudadano también es llamado a la protección de los recursos naturales y la conservación del ambiente (C.P. Arts. 95-8), que incluso apela a la dimensión del Homo consumens.

Hay aspectos en la protección relacionados con ciertas circunstancias excepcionales, por ejemplo, lo ocurrido con la emergencia invernal declarada a finales de 2010 (Decreto 4580 de 2010) ${ }^{4}$, que permiten que el Presidente y su ministros legislen temporalmente con el fin de conjurar la crisis ambiental.

Para el cumplimiento de estos deberes, además de declarar que el Estado es propietario del subsuelo y los recursos naturales no renovables $^{5}$ (sic), se alude, en el artículo 334 (mod. por el Acto Legislativo 03 de 2011, cfr. Sentencia C-288 de $2012^{6}$, que instituye el Estado Financiero de Derecho) a la intervención estatal en ciertos sectores (explotación de recursos naturales, uso del suelo, producción, utilización y consumo de bienes) para la preservación (sic, debería ser conservación pues la preservación significaría dejarlo intocado) de un ambiente sano. Dentro del modelo de intervención, el Estado tiene como deber la solución de necesidades del saneamiento ambiental y de agua potable como finalidad (C.P. Art. 366).

En cuanto a las autoridades que a nivel constitucional se erigen para la protección del ambiente, están las del nivel nacional (C.P. Arts. 334 y 339) y las Corporaciones Autónomas Regionales que se prevén en el artículo 150 numeral 7 y la Corporación del Río Grande de la Magdalena (C.P. Art. 331). Existen, además, funciones ambientales en las Asambleas Departamentales (C.P. Art. 300, num. 2), Concejos Municipales (C.P. Art. 313, num. 9), los Distritos Especiales (C.P. Arts. 322 y 328, mod. A.L. 02 de 2007) y los consejos de los territorios indígenas (C.P.

\footnotetext{
${ }^{4} \mathrm{Si}$ bien la situación invernal fue grave y extraordinaria, existen elementos de base que cuestionan el manejo ambiental que brindan las autoridades que deben protegerlo.

${ }^{5}$ Esta categoría está en cuestionamiento pues, además del término recurso, supone la infinitud del agua, aire y oxígeno.

${ }^{6}$ Es importante advertir que el principio de sostenibilidad fiscal afecta derechos y puede conducir a restricciones en los estándares de protección al ambiente no sólo por restricciones en el gasto sino también por necesidades de recursos, como ocurre, actualmente, con las regalías. Se crea el dilema extorsivo según el cual no habrían recursos para ciertas actividades porque no se explotan el ambiente en los niveles e intensidad que se pretende.
} 
Arts. 330-5, ahora con la competencias previstas en el Decreto 1953 de 2014, en materia de saneamiento básico).

Desde la perspectiva del control en sus diversas facetas, la Contraloría General de la República desarrolla la labor de diagnóstico de la situación ambiental (C.P. Art. 268, num. 7) y la Procuraduría dinamiza la defensa del ambiente (C.P. Art. 277-4) junto con el Defensor del Pueblo (C.P. Art. 282, num 5). A nivel financiero, además de lo que se prevé en materia de regalías (A.L. 5 de 2011), el artículo 317 consagra la posibilidad de gravar la propiedad inmueble y establecer la contribución de valorización cuyos recursos se destinarán al manejo y conservación del ambiente y de los recursos naturales renovables (sic).

De la revisión normativa se observa que la Constitución propicia un entorno favorable a la protección del ambiente (Marquardt, 2011) con facultades y herramientas en los diferentes niveles del Estado y, obviamente, en el plano administrativo en donde está, si se quiere, el primer nivel dispositivo del ambiente. No obstante, incurre en unas impropiedades terminológicas y de concepción que facilitan vulneraciones al mismo y subordinan el ambiente a otros propósitos, entre ellos, precisamente los que tienen que ver con la denominada Constitución económica. Así, sobre una base de explotación capitalista, incorpora unas normas de gestión ambiental; lo que prima en la reflexión es la primera, lo segundo es subsidiario aunque ahora problemático.

\section{¿Un mundo licenciado o licencioso?}

Realizando una exploración de las acepciones que se encuentran en el diccionario de la Real Academia de la Lengua en torno al concepto de licencia, además de encontrar la de autorización para realizar una actividad, aparece la de "abusiva libertad en decir u obrar" (Real Academia de la Lengua, 2014) que pareciera estar más asociada al proceso actual. La definición contenida en el artículo 50 de la Ley 99 de 1993 y desarrollada en el artículo 3 del Decreto 2041 de $2014^{7}$, expedido con el propósito de optimizar los procedimientos (léase licencia express), alude

\footnotetext{
${ }^{7}$ Debe decirse que la reglamentación de este tema ha sufrido constantes cambios algunos de ellos curiosamente a finales de gobierno. Es así como se han expedido los Decretos 1753 de 3 de agosto de 1994, 1728 de 6 de agosto de 2002, 1180 de 10 de mayo de 2003,1220 de 21 de abril de 2005 y 2820 de 5 de agosto de 2010.
} 
a ella como una autorización otorgada por la autoridad ambiental para la ejecución de una obra o actividad y sujeta a unos requisitos de manejo; debe, sin duda, ser una exigencia previa a cualquier intervención en el ambiente. Dicho artículo incorpora un intensificador para la licencia, consistente en que el deterioro sea grave a los "recursos naturales renovables o al medio ambiente o introducir modificaciones considerables o notorios al paisaje"s.

Según se indicó, la Ley 99 de 1993 (Arts. 49 y ss), modificados por los artículos 223, 224 y $225^{9}$ de la Ley 1450 de 2011 y los Decretos 330 de 2007 y 2041 de 2014, constituyen la base actual del proceso de licenciamiento. Para Mesa (2011b), el proceso de licenciamiento ambiental supone un análisis inter, multi y transdisciplinar del operador jurídico. El análisis jurídico no puede ser remplazado o ignorado por prácticas institucionales de reducción de tiempo en busca de eficacia y/o eficiencia (principios de la gestión administrativa). Encuentra en este proceso una serie de fallas formales y sustanciales como la formatitis, la falta de coordinación y armonía, la falta de rigor, la mala redacción, la debilidad en las sanciones y el carácter mecánico del proceso (Mesa 2011a, p. 194 y 195). La institucionalidad construida ha sido débil, y ahora, al amparo de las Leyes 1444 y 1450, ambas de 2011 y el Decreto 2041 de 2014, se revela que el interés estatal es acelerar el trámite mediante la reducción de términos, por un lado, y por otra, a través de la creación de una Autoridad Nacional de Licencias Ambientales -ANLA- (Decretoley 3573, 2011) por fuera de la labor propia del Ministerio de Ambiente y Desarrollo Sostenible, lo que enfatiza su debilidad. No sobra indicar que dentro de las curiosidades de la Ley 1450, si el término de 90 días (ya no 120 días) entre el Auto de trámite de toda la información y la decisión se rebasa, se conforma un Comité integrado por el Ministro de Ambiente y Desarrollo Sostenible o su delegado, el Director del Departamento Nacional de Planeación o su delegado, y el Ministro cabeza del sector al que corresponde el proyecto del caso o su delegado, para elaborar un plan de acción para la decisión. El Decreto 2041, por su parte,

\footnotetext{
${ }^{8}$ Nótese aún la impropiedad en el uso de los términos, insistiendo aún en 2014 en las expresiones redundantes y parcializadas de "medio ambiente".

${ }^{9}$ Curiosamente, ninguna de las normas de la Ley 1450 de 2011 que modifica la Ley 99 de 1993 ha sido demandada hasta el momento. Lo anterior conforme a la revisión realizada el 10 de noviembre de 2014. http:// www.corteconstitucional.gov.co/secretaria/ConsultaC/normas.php
} 
responde a la exigencia de celeridad que aparece como la principal preocupación de este trámite (El Tiempo, 2014).

Como quedó expresado, se ha reducido el ámbito de proyectos, obras o actividades que son susceptibles de licencia, lo que, sin duda, limita la protección administrativa, pues muchos proyectos, obras y actividades no requieren licencia a pesar del impacto que producen.

En relación con el trámite, los denominados estudios ambientales, a saber, el Diagnóstico de Alternativas Ambientales -DAA- y el Estudio de Impacto Ambiental -EIA- (Arts. 56 y 57 de la Ley 99 de 1993; arts. 13, 17 a 22 del Decreto 2041) son presentados por el interesado ante la autoridad ambiental, lo cual genera de entrada un sesgo, pues es el particular quién señala cuál es el grado de afectación de su proyecto. El trámite plantea al inicio una división entre los proyectos, obras o actividades que requieren DAA (16 clases) y los restantes, para los que se exigiría simplemente el EIA. En cuanto a los primeros, la Autoridad establece cuál es la alternativa sobre la que se realizará el EIA, que es el estudio elaborado por el solicitante y conforme a una metodología y unos términos de referencia, sobre el que se toman las decisiones. Es decir, la autoridad ambiental cede al particular la elaboración del pilar básico y sólo eventualmente verificará la información sobre la cual se soporta. Ello da lugar al Auto de Inicio y a un requerimiento a otras autoridades que, curiosamente, se puede dejar de recibir, pasado lo cual la Autoridad declara reunida toda la información y tendrá un término de 30 días según el Decreto 2041 (Art. 25), de 120 días según la Ley 99 de 1993 (Art. 58) y de 90 días de acuerdo con la reforma contenida en la Ley 1450 (Art. 224) para pronunciarse. Hasta el momento, la Autoridad sólo cuenta con la información del solicitante y este escenario no ha cambiado sustancialmente pero ya existen términos perentorios para el pronunciamiento que termina generando el trámite especial contenido en el artículo 224, parágrafo 1, de la Ley 1450, todo lo cual se refuerza con la perentoriedad que exige ahora el Decreto 2041 de 2014, aplicable a partir de 2015. Pero la celeridad de que se habla constituye sólo un prurito pues ni si quiera el país más capitalista obra con tal apresuramiento. Según una investigación (Bermúdez, 2013), en Estados Unidos el trámite puede ser de entre 36 y 84 meses al paso que en Australia está entre 12 a 36 meses y en Canadá corresponde a un mínimo de 6 meses. En el entorno latinoamericano, países como Ecuador destinan 
de entre 6 a 10 meses en el trámite y en Perú puede llegar a 24 meses. Chile es el país con un menor tiempo (4 meses).

No puede perderse de vista que, de acuerdo con los datos suministrados por la $\mathrm{ANLA}^{10}$, durante el período de 2007 a 2012, ante la autoridad ambiental (el Ministerio o la ANLA) se presentaron 741 solicitudes de licencias, de las cuales fueron otorgadas 699 y negadas 46, es decir, cerca del 94\% de las solicitudes son otorgadas, una cifra reveladora. En cuanto a la distribución por obras, actividades o proyectos, siguiendo la clasificación de la ANLA, sectorialmente se encuentra que los proyectos respecto de los cuales se solicitaron más licencias durante el período mencionado son: los agroquímicos con 326 aprobaciones y 25 rechazos; le siguen los proyectos de hidrocarburos con 263 aprobaciones y 13 rechazos y, en tercer término, infraestructura con 55 aprobaciones y tan sólo una negativa. Se destaca en el caso de la minería, 5 aprobaciones e igual número de negaciones.

Con el fin de examinar un proceso actual de licenciamiento y cotejarlo frente a los estudios realizados en la materia, se seleccionó una muestra de resoluciones recientes adoptadas por la nueva autoridad ${ }^{11}$. Las consideraciones preliminares incluyen unos antecedentes del trámite, una justificación normativa y jurisprudencial de las etapas surtidas, los fundamentos de la protección al medio ambiente, los principios y la competencia de la ANLA. Posteriormente, se remite al contenido del concepto técnico, en cuanto a la acreditación de la documentación solicitada. Trae un capítulo referido a la demanda de recursos naturales requeridos para la ejecución del proyecto (por ejemplo, concesión de aguas superficiales, permiso de vertimiento, aprovechamiento forestal, ocupación de cauces, manejo de residuos, medidas de manejo ambiental, etc.). Finalmente, la parte resolutiva incorpora, además del otorgamiento, sendas decisiones de manejo ambiental y límites y autorizaciones (un promedio de 40 artículos en la parte resolutiva). En suma, la li-

\footnotetext{
${ }^{10}$ Respuesta de la Oficina Asesora Jurídica de la ANLA del 2 de octubre de 2012 a un derecho de petición del 7 de septiembre de 2012

${ }^{11}$ Se tuvieron en cuenta las Resoluciones 976 de 29 de agosto de 2014, Gran Tierra Energy Colombia Ltd, otorgada; 958 de 22 de agosto de mayo de 2014, Yuma Concesionaria, otorgada; 932 de 9 de agosto de 2014, TECPETROL, otorgada; 857 de 30 de julio de 2014, Shell, otorgada; 768 de 16 de julio de 2014, Concesionario Ruta del Sol, otorgada y 736 de 8 de julio de 2014, Autopistas La Sabana, otorgada. Cfr. Boletines ANLA, en http://www.anla.gov.co/contenido/categoria.aspx?catID=1295. Consulta realizada el 11 de noviembre de 2014 .
} 
cencia ambiental, junto con los documentos y demás actuaciones que hacen parte de ella y que la presuponen, tienen como propósito el de hacer viable los proyectos, obras o actividades que surgen de la iniciativa privada de los interesados y con base en los estudios realizados por la empresa sin utilizar indicadores ambientales específicos, parcialidad en los criterios (los del interesado), las sinergias que se presentan y reales estudios de impacto (Leal, 2013).

A este panorama, deben sumarse ciertas decisiones de constitucionalidad o en sede de tutela en las que la Corte ha considerado el proceso de licenciamiento y la licencia como un "sagrado" derecho derivado del sagrado derecho de propiedad o apropiación. Si bien ha negado que se produzca el silencio administrativo positivo (Sentencia C-328, 1995) y que, además, el Diagnóstico de Alternativas Ambientales no deba ser eliminado (Sentencia C-035, 1999), ha señalado que es factible reducir exigencias cuando se declara el estado de emergencia económica, social o ambiental (Sentencia C-328, 1999) e incluso ha estimado que la taxatividad en las causales de negación de la licencia contenidas en el Código de Minas (Art. 213 de la Ley 685 de 2001) es constitucionalmente válida (Sentencia C-813, 2009). Adicionalmente, admitió la posibilidad de expedir licencias ambientales a proyectos que afecten el sistema nacional de parques (Art. 52, num. 9, de la Ley 99 de 1993, Cfr. Sentencia C-746, 2012).

En todo caso, la aprobación de una licencia es susceptible de protección a nivel administrativa o judicial a través de los recursos en vía gubernativa, la revocatoria de la licencia o autorización (Art. $45^{12}$ de la Ley 1333 de 2009), la acción de nulidad de la licencia, la acción de tutela (Sentencias SU-039 de 1997, T-955 de 2003, T-547 de 2010), la acción de cumplimiento y la acción popular. Adicionalmente, y dentro de las herramientas administrativas de protección, se encuentran las infracciones ambientales, reguladas en la Ley 1333 de 2009. En este punto debe resaltarse lo previsto en el parágrafo del artículo 1 y en el parágrafo del artículo 5 respecto a la presunción de culpa o dolo del infractor en esta clase de infracciones, normas declaradas exequibles (Sentencia C-595, 2010).

${ }^{12}$ Esta norma fue declarada exequible. Se cuestiona el principio de legalidad de las sanciones. 


\section{La participación}

Las normas constitucionales aludidas, el Convenio 169 (1989) de la OIT, la Ley 70 (1993), así como la Declaración de Río (principio 10, 1992), plantean la universalidad en la información, la oportunidad de la participación y el acceso efectivo a los recursos administrativos y judiciales. La Ley 99 de 1993, en sus artículos 1, numerales 10 y 12, y 69 a 76, reglamentada por el Decreto 330 de 2007, escinden el proceso general de participación del propio de consulta previa a los grupos étnicos. En cuanto a la participación ciudadana, en punto a licencias, la Corte Constitucional ha especificado que las consultas populares no obligan a la autoridad (Sentencia T-123, 2009). Es diciente, además, que de las resoluciones examinadas sólo en una se haya practicado una audiencia pública (Resolución 736 de 2014) y de manera muy tangencial).

La participación a través de las audiencias públicas. La Ley 99 de 1993 establece un esquema general de intervención a toda persona natural o jurídica (Arts. 69 y 70). Es, sin embargo, en las audiencias públicas ambientales, y previo a la adopción de una licencia o permiso ambiental (Art. 72) o como mecanismo de seguimiento de la autorización (Art. 3 del Decreto 330 de 2007), en las que realmente puede afirmarse que se concreta un derecho de participación cualitativamente importante. Paradójicamente, el parágrafo del artículo 2 del Decreto 330 de 2007 contempla que la "audiencia pública no es una instancia de debate, ni de discusión", haciéndole perder su horizonte y sentido y propiciando una visión netamente informativa que se ve refrendada con la instalación y desarrollo de la misma (Art. 13 del Decreto 330).

Adicionalmente, los artículos 72 de la Ley 99 de 1993 y 5 del Decreto 330 de 2007 establecen una cualificación del sujeto que puede solicitarla, con lo cual limita la expresión ciudadana (el Procurador General o el Delegado para Asuntos, el Ministro del Medio Ambiente, las demás autoridades ambientales, los gobernadores, los alcaldes o por lo menos cien (100) personas o tres (3) entidades sin ánimo de lucro). Además de excluir un número plural de personas menor a 100 o de entidades sin ánimo de lucro menores a tres, se excluye a los órganos de control fiscal, que si bien no pueden ejercer un control concomitante, sí contarían con elementos de juicio e interés para que la misma se convocara. Una vez 
admitida la convocatoria a la audiencia es susceptible de ser rechazada por razones de pertinencia (Art. 6 del Decreto 330, tema igualmente controversial); se debe practicar la misma con una antelación de 30 días a la expedición de la decisión.

En este caso, es palmario que la visión amplia de participación a nivel constitucional termina reducida en una instancia informativa y no deliberativa.

La consulta previa. Es en los territorios de los grupos étnicos (indígenas, raizales, gitanos y afrodescendientes [Sentencia T-745, 2010] ${ }^{13}$ en donde existe una tensión fuerte de explotación del ambiente. Lo étnico ha resurgido como un elemento que cuestiona la visión etnocéntrica que guió el proceso expansivo de la conquista, colonia e imperialismo (una sola visión y un solo desarrollo) y, en sí mismo, plantea un desarrollo fundado en relaciones centradas en el respeto de la naturaleza como un ser vivo (Marquardt, 2011, p. 279). La Constitución deja una huella para materializar ese reconocimiento (Arts. 7, 8, 10, 63, 68, 286, 329, 330) abordando temas como la diversidad, la autonomía, el territorio y el patrimonio cultural.

La consulta previa recrea el debate que se ha intensificado desde hace más de seis años en relación con los actos que son susceptibles de ser sometidos a consulta previa, entre otras razones por las consecuencias que produce la omisión de ese procedimiento especial y teniendo en cuenta que es un derecho fundamental. La Corte Constitucional ha delineado las facetas de la consulta previa, su aplicación, procedimiento, necesidad, entre otros elementos relevantes, en un comienzo respecto de acciones específicas (Sentencias T-428 de 1992, T-652 de 1998, SU-383 de 2003, entre otras) que los afectan y luego frente a actos legislativos (Sentencia C-702, 2010), leyes (Sentencia C-366 de 2011, entre otras), incluyendo las que adoptan el Plan Nacional de Desarrollo (Sentencia C-461, 2008) o aquellas aprobatorias de tratados internacionales (Sentencia C-615, 2009), así como la inaplicación del Decreto 1320 de 1998 (Sentencia. T-737, 2005).

\footnotetext{
13 Además de ocupar territorios estratégicos, según el censo de 2005 y otras fuentes, la población afrodescendiente está entre los 7 y 9 millones (19\% de la población), la indígena 1’378.884 (3,4\% de la población), los raizales 18 mil y los gitanos 4382 .
} 
Debe señalarse que el proceso de consulta previa constituye un mecanismo especial de convocatoria a los pueblos que se ven afectados directamente por una medida de carácter normativo, lo cual no anula el derecho de participación general, previsto para toda la población, respecto de aquellas medidas en las que tenga interés, bien porque los afectan indirecta o mediamente, o bien porque optan por ese derecho de intervenir en asuntos públicos como un principio fundamental de una democracia participativa (Preámbulo, art. 1, Constitución Política). Un proyecto o norma que afecta directamente a las comunidades y que no surtió el proceso de consulta previa estaría viciado en los términos en que lo ha declarado la Corte Constitucional respecto de ciertas iniciativas que se convirtieron en ley (Cfr. Sentencia C-175 de 2009, entre otras). Para que ello tenga un real sentido dentro de nuestro ordenamiento, la afectación directa implica, entonces, la comprobada especificidad material de la norma que se proyecta expedir, bien porque incluye un aspecto sensible (la tierra y su propiedad) o bien porque se hace concreto desde el punto espacial o territorial. Todos aquellos temas que comportan una afectación genérica o mediada no serían objeto del proceso.

De lo anterior se colige no sólo la importancia de la consulta previa sino la especial sensibilidad que ha desplegado la Corte Constitucional con el fin de preservar la diversidad étnica y cultural de estos pueblos (Sentencia C-366 de 2011, citada). Ahora bien, desde el punto de vista cualitativo, además de establecer ese ámbito, no puede escapar a estas reflexiones la razón de ser de este procedimiento, que no es otra que hacer concreta la protección que debe brindar el Estado a la diversidad étnica y cultural y en la que emergen las siguientes características derivadas de precisiones jurisprudenciales, doctrinales y normativas, como son su carácter de previa, ser un derecho fundamental, garantista, no confrontacional, sustancial, de buena fe, informada, actual y participativa (Sentencia C-461 de 2008, citada). Esto exige, entre otros aspectos y en consonancia con la Ley 1381 de 2010, que la actuación que se adelante sea en la lengua propia. Ahora bien, en la sentencia T-254 de 1994 (Sentencia T-254, 1994) se realiza un esfuerzo entre lo unitario y lo autónomo y las primacías y prevalencias existentes. En este marco sería viable plantear el derecho de veto y la objeción cultural respecto de un proyecto, obra o actividad que pueda conducir al exterminio (Sentencia T-129, 2011). 
Actualmente, no existe una norma especial de consulta previa (que correspondería a una ley estatutaria). El Decreto 1320 de 1998 ha sido inaplicado y existe una Directiva, la número 10 de 2013, que no fue consultada y que regula esta clase de procesos, así como el Decreto 2613 de 2013. Pero no es la autoridad administrativa quién escucha ese clamor de los pueblos sino que ha debido ser la jurisprudencia la que propicie este proceso (Sentencia T-1080, 2012).

\section{El seguro ecológico}

Con fundamento en el principio de responsabilidad, sería deseable que la licencia estuviese acompañada de un afianciamiento por los eventuales daños que puedan producirse. No obstante, como lo señala el profesor Mesa, los aseguradores no conocen a profundidad la magnitud de los riesgos (Mesa, 2010). Lo previsto en la Ley 491 de 1999 contempla una responsabilidad demasiado limitada en la medida en que lo enfoca a "cubrir los perjuicios económicos cuantificables a personas determinadas". Aunque relaciona la obligatoriedad del seguro con la licencia (Art. 3), es un tema que no se debate en el proceso de licenciamiento, ni si quiera se menciona, a pesar de la trascendencia que tiene o que debería tener. $\mathrm{Su}$ estructura es netamente mercantil y, por lo tanto, no incorpora los elementos de una típica responsabilidad ambiental. Es así como los beneficiarios, la determinación del daño, el destino de la indemnización y la prescripción configuran un régimen de responsabilidad del derecho comercial (que no sólo es la legislación complementaria sino la principal), que no es precisamente el que debería corresponder a un seguro ambiental. En realidad, no estamos en presencia de un seguro de esa naturaleza ni en él se reconoce un atisbo de justicia ambiental.

Una real dimensión de los daños ambientales en que puede incurrir una empresa y que resulta aleccionador es la condena a la empresa petrolera Chevron por 9,5 mil millones de dólares por los daños producidos en la provincia de Sucumbíos (La Jornada, 2012; Juicio No. 2011-0106, 2012) y que está en un telúrico proceso de cumplimiento y contraataques de la empresa contaminante, suma que subió a 19 mil millones de dólares pues la Chevron no ha reconocido la dimensión del daño ni ha ofrecido disculpas. No sólo es el monto de la condena sino el reconocimiento de la cantidad de agresión al ambiente sobre una zona de dos millones hectáreas. 


\section{CONCLUSIONES}

De lo indicado se colige que el proceso de licenciamiento no está enmarcado en su real defensa sino, más bien, en su cotidiana ofensa y ello lo reconoce el propio director de la ANLA a quien realmente le preocupa la celeridad en la decisión y los intereses de los inversionistas; habla como un funcionario del empresariado y no como jefe de una autoridad ambiental (Iregui, 2014 en contra Vargas, 2014). Esta visión, así como lo previsto en el Decreto 2041 de 2014, y el propio análisis que realiza la ANLA pueden estar creando un estado de cosas inconstitucional en materia ambiental.

En efecto, con la revisión de la protección administrativa a través del proceso de licenciamiento, los principios básicos de la justicia ambiental se desvanecen. Al revisar el proceso de licenciamiento, se ha considerado que más que la precaución (Romero, 2013) prima el principio de in dubio pro licencia. Dicho trámite no responde a los principios de solidaridad y responsabilidad, pues los análisis tanto de los estudios que se realizan como del proceso en donde se escucha a los afectados, no plantean dimensiones reales de la problemática y las afectaciones al ambiente, tanto a otros sujetos (en su concepción amplia y biocéntrica) como a las generaciones futuras. De esta manera, el esquema de licenciamiento es la más palpable muestra de que prima una visión antropocéntrica, eco-neoliberal y eco-capitalista, cuya ideología lo impregna en todos sus aspectos y fases. No importan tampoco los seres humanos actuales que habitan el territorio ni los arraigos que allí tengan, desmoronando así, la pirámide de prioridades (Necesidades Básicas Humanas Actuales, en primer lugar) o, en otras palabras, se promueve un desarrollo sostenible y no una sostenibilidad ambiental (Romero, 2012, p. 209).

De otro lado, el licenciamiento es un proceso caracterizado por su sectorialidad. A pesar de que se trata de una actividad que debe ser vista desde las perspectivas integral y diversa, priman los enfoques restringidos a la explotación de un recurso en el que quien impone las condiciones a través de los estudios ambientales es el particular solicitante. Si a esto se le suma, la premura conminatoria que incorpora la Ley 1450 de 2011, una ley que adopta el Plan Nacional de Desarrollo 
pero que sin embargo modifica la Ley 99 de 1993, y que se refuerza en el Decreto 2041, se está en presencia de un trámite notarial que persisten en la formalidad ya detectada y el valor agregado a la protección del ambiente es mínimo. Aún en vigencia de otras normas, el porcentaje de otorgamiento de licencias frente a la negación de las mismas es demasiado alto y revela la laxitud existente. La institucionalidad se debilita aún más, y particularmente lo hace la protección cuando al proceso de licenciamiento ambiental escapan ciertas actividades y cuando no existe un verdadero dimensionamiento de los daños que se producen.

Adicionalmente, la propia institucionalidad y las normas no crean una capacidad real de escuchar a los otros, cuando ello se produce y es necesario. Hay otros intereses más fuertes y contundentes que la minimizan y la hacen inaudible, máxime si actualmente existe una presión extorsiva pues la existencia de recursos está ligada a la explotación inmisericorde del ambiente. Tal vez en la consulta previa a los grupos étnicos, la protección se refuerce en algo pues el etnocidio que puede producir una intervención agresiva, haría posible ejercer el derecho de veto. En ambos casos, sin embargo, se maneja la presión de la "mayoría" (que representaría el interés general) sobre la "minoría" (que estarían representando el interés particular) que constituye un falso dilema y una falso planteamiento. Está visto que en la raíz del acceso al ambiente existe un interés particular específico guiado por el ánimo de lucro.

Se ha considerado entonces, que antes de la aplicación del principio de precaución, se está en presencia de dos antiprincipios como el de in dubio pro explotación y el sagrado derecho a la licencia.

A todo esto, no puede pasarse por alto que el economista británico, Nicholas Stern, autor del informe Stern (2007) sobre cambio climático, una entrevista reciente afirmó que "si todos los factores se consideran, de pronto puede resultar que es más rentable dejar esos recursos enterrados que explotarlos" (Stern, 2012; igualmente en Fierro, 2012, p. 220). La "posesión" y el acceso al ambiente podría ser entendida según se plantea en El Principito, como un acto de afecto en el que el otro (la rosa, los volcanes y los baobabs) son sujetos (no objetos) a los que hay que cuidar y que en esa relación también se cuidan. 


\section{BIBLIOGRAFÍA}

Arnaud, A. (2000). Entre modernidad y globalización. Bogotá, D.C.: Universidad Externado de Colombia.

Attfiel, R. (2010). La ética ambiental y la sostenibilidad global. En H. A. Have, Ética ambienal y políticas internacionales, 75-96. París: Unesco.

Bermúdez, A. (2013). La silla vacía. Obtenido de http://lasillavacia.com/historia/el-debate-sobre-las-licencias-ambientales-expres-44099

Castro, G. (2014). Nuestra guerra ajena. Bogotá, D.C.: Planeta.

Fierro, J. (2012). Políticas Mineras en Colombia. Bogotá, D.C.: Ilsa.

Hardin, G. (1995). La tragedia de los comunes. Gaceta Ecológica, 38, 48.

Houtart, F. (2011). El concepto de Sumak Kawsay. Espacio Crítico, (2), 23.

Ibañez, A., \& Muñoz, J. (2010). The Persistence of Land Concentration in Colombia. En M. Bergsmo, C. Rodríguez, K. Pablo, \& M. Saffon, Distributive Justicia in Transitions (279-310). Oslo: Torkel Opsahl.

Iregui, F. (2014, 24 de septiembre). No es un proceso express. El Espectador. Recuperado de: http://www.elespectador.com/noticias/medio-ambiente/ no-un-proceso-expres-articulo-518743

Jonas, H. (1995). El principio de responsabilidad. Barcelona: Herder.

Leal, L. (2013, 13 de julio). Licencias ambientales a la carta. UN Periódico. Recuperado de: http://www.unperiodico.unal.edu.co/dper/article/licencias-ambientales-a-la-carta.html

Licencias ambientales "exprés", entre aplausos y críticas. (2014 ,10 de octubre). El Tiempo. Recuperado de: http://www.eltiempo.com/economia/sectores/ debate-de-licencias-ambientales-expres/14666297

Marquardt, B. (2011). Los dos Siglos del Estado Constitucional en América Latina. Bogotá, D.C.: Universidad Nacional de Colombia.

Martínez, J. (1994). De la economía ecológica al ecologismo popular. Barcelona: Icaria.

Melo, C. (2009). Deliberación y democracia: el futuro de la democracia deliberativa. IX Congreso AECPA. Málaga.

Mesa, G. (2010). Derechos ambientales en perspectiva de integralidad: concepto y fundamentación de nuevas resistencias actuales hacia el estado ambiental de derecho. Bogotá, D.C: Universidad Nacional. 
Mesa, G. (2011a). Análisis constitucional y legal para la gestión de pasivos ambientales. En G. Mesa Cuadros, Elementos para una justicia ambiental y el Estado Ambiental de derecho. Bogotá, D.C.: Universidad Nacional.

Mesa, G. (2011b). El proceso de licenciamiento ambiental o de cómo no debe hacerse gestión ambiental en Colombia. En GIDCA, Elementos para una teoría de la Justicia Ambiental y el Estado Ambiental de Derecho, 189211. Bogotá, D.C.: Universidad Nacional.

Negri, A., \& Hardt, M. (2011). Common wealth, el proyecto de una revolución del común. Madrid: Akal.

Organización de Naciones Unidas. (1992). Informe de la Conferencia de Naciones Unidas sobre Medio Ambiente y Desarrollo. Recuperado de: http:// www.unesco.org/education/nfsunesco/pdf/RIO_S.PDF

Organización Internacional del Trabajo. (1989). Convenio 169. Sobre Pueblos Indígenas y Tribales en Países Independientes. Recuperado de: http:// www.oit.org.pe/WDMS/bib/publ/libros/convenio_169_07.pdf

Piccoli, G. (2008). El sistema del Pájaro, paramilitarismo y conflicto social. Bogotá, D.C.: Ilsa.

Proudhon, P. (1996). Qu'est-ce que la proprieté? Paris: Garnier-Flammarion.

Real Academia de la Lengua. (8 de noviembre de 2014). Real Academia Española. Obtenido de http://lema.rae.es/drae/?val=licencia

República de Colombia. Congreso de la República. Acto Legislativo 02. (Julio 6 de 2007). Por medio del cual se modifican los artículos 328 y 356 de la Constitución Politica de Colombia. Diario Oficial 46.681. Bogotá, D. C.: Imprenta Nacional de Colombia.

República de Colombia. Congreso de la República. Acto Legislativo 03. (Julio 1 de 2011). Por el cual se establece el principio de la sostenibilidad fiscal. Diario Oficial 48.117. Bogotá, D. C.: Imprenta Nacional de Colombia.

República de Colombia. Congreso de la República. Acto Legislativo 05. (Julio 18 de 2011). Por el cual se constituye el Sistema General de Regalías, se modifican los artículos 360 y 361 de la Constitución Política y se dictan otras disposiciones sobre el Régimen de Regalías y Compensaciones. Diario Oficial 48.134. Bogotá, D. C.: Imprenta Nacional de Colombia.

República de Colombia, Congreso de la República. Ley 70 (27 de agosto de 1993). Por la cual se desarrolla el artículo transitorio 55 de la Constitución Política. Diario Oficial 41.013. Bogotá, D. C.: Imprenta Nacional de Colombia. 
República de Colombia, Congreso de la República. Ley 99 (22 de diciembre de 1993). Por la cual se crea el Ministerio del Medio Ambiente, se reordena el Sector Público encargado de la gestión y conservación del medio ambiente y los recursos naturales renovables, se organiza el Sistema Nacional Ambiental, SINA, y se dictan otras disposiciones. Diario Oficial 41.146. Bogotá, D. C.: Imprenta Nacional de Colombia.

República de Colombia, Congreso de la República. Ley 491 (13 de enero de 1999). Por la cual se establece el seguro ecológico, se modifica el Código Penal y se dictan otras disposiciones. Diario Oficial 43.477. Bogotá, D. C.: Imprenta Nacional de Colombia.

República de Colombia, Congreso de la República. Ley 685 (15 de agosto de 2001). Por la cual se expide el Código de Minas y se dictan otras disposiciones. Diario Oficial 45.273. Bogotá, D. C.: Imprenta Nacional de Colombia.

República de Colombia, Congreso de la República. Ley 1333 (21 de julio de 2009). Por la cual se establece el procedimiento sancionatorio ambiental y se dictan otras disposiciones. Diario Oficial 47.417. Bogotá, D. C.: Imprenta Nacional de Colombia.

República de Colombia, Congreso de la República. Ley 1381 (25 de enero de 2010). por la cual se desarrollan los artículos $7^{\circ}, 8^{\circ}, 10$ y 70 de la Constitución Política, y los artículos $4^{\circ}, 5^{\circ}$ y 28 de la Ley 21 de 1991 (que aprueba el Convenio 169 de la OIT sobre pueblos indigenas y tribales), y se dictan normas sobre reconocimiento, fomento, protección, uso, preservación y fortalecimiento de las lenguas de los grupos étnicos de Colombia y sobre sus derechos lingüisticos y los de sus hablantes. Diario Oficial 47.603. Bogotá, D. C.: Imprenta Nacional de Colombia.

República de Colombia, Congreso de la República. Ley 1444 (4 de mayo de 2011). Por medio de la cual se escinden unos Ministerios, se otorgan precisas facultades extraordinarias al Presidente de la República para modificar la estructura de la Administración Pública y la planta de personal de la Fiscalía General de la Nación y se dictan otras disposiciones. Diario Oficial 48.059. Bogotá, D. C.: Imprenta Nacional de Colombia.

República de Colombia, Congreso de la República. Ley 1450 (16 de junio de 2011). Por la cual se expide el Plan Nacional de Desarrollo, 2010-2014. Diario Oficial 48.102. Bogotá, D. C.: Imprenta Nacional de Colombia.

República de Colombia. Consejo Superior de la Judicatura (2010). Constitución Política de Colombia de 1991. Bogotá: Imprenta Nacional de Colombia. 
República de Colombia. Corte Constitucional. Sentencia C-035. Enero 27 de 1999. Magistrado ponente: Antonio Barrera Carbonell.

República de Colombia. Corte Constitucional. Sentencia C-175. Marzo 18 de 2009. Magistrado ponente: Dr. Luis Ernesto Vargas Silva.

República de Colombia. Corte Constitucional. Sentencia C-283. Mayo 14 de 2014. Magistrado ponente: Jorge Iván Palacio Palacio.

República de Colombia. Corte Constitucional. Sentencia C-288. Abril 18 de 2012. Magistrado ponente: Luis Ernesto Vargas Silva.

República de Colombia. Corte Constitucional. Sentencia C-313. Mayo 29 de 2014. Magistrado ponente: Gabriel Mendoza Martelo.

República de Colombia. Corte Constitucional. Sentencia C-328. Julio 27 de 1995. Magistrado ponente: Eduardo Cifuentes Muñoz.

República de Colombia. Corte Constitucional. Sentencia C-328. Mayo 12 de 1999. Magistrado ponente: Martha Sáchica De Moncaleano.

República de Colombia. Corte Constitucional. Sentencia C-366. Mayo 11 de 2011. Magistrado ponente: Luis Ernesto Vargas Silva.

República de Colombia. Corte Constitucional. Sentencia C-461. Junio 2 de 2008. Magistrado ponente: Juan Carlos Henao Pérez.

República de Colombia. Corte Constitucional. Sentencia C-595. Julio 27 de 2010. Magistrado ponente: Jorge Iván Palacio Palacio.

República de Colombia. Corte Constitucional. Sentencia C-615. Septiembe 2 de 2009. Magistrado ponente: Dr. Humberto Antonio Sierra Porto.

República de Colombia. Corte Constitucional. Sentencia C-670. Septiembre 10 de 2014. Magistrado ponente: María Victoria Calle Correa.

República de Colombia. Corte Constitucional. Sentencia C-702. Septiembre 6 de 2010. Magistrado ponente: Dr. Jorge Pretelt Chaljub.

República de Colombia. Corte Constitucional. Sentencia C-703. Septiembre 6 de 2010. Magistrado ponente: Gabriel Mendoza Martelo.

República de Colombia. Corte Constitucional. Sentencia C-746. Septiembre 26 de 2012. Magistrado ponente: Luis Guillermo Guerrero Pérez.

República de Colombia. Corte Constitucional. Sentencia C-813. Noviembre 18 de 2009. Magistrado ponente: Jorge Pretelt Chaljub.

República de Colombia. Corte Constitucional. Sentencia SU-039. Febrero 3 de 1997. Magistrado ponente: Antonio Barrera Carbonell. 
República de Colombia. Corte Constitucional. Sentencia SU-383. Mayo 13 de 2003. Magistrado ponente: Dr. Álvaro Tafur Galvis.

República de Colombia. Corte Constitucional. Sentencia T-123. Febrero 24 de 2009. Magistrado ponente: Clara Inés Vargas Hernández.

República de Colombia. Corte Constitucional. Sentencia T-129. Marzo 3 de 2011. Magistrado ponente: Jorge Iván Palacio Palacio.

República de Colombia. Corte Constitucional. Sentencia T-254. Mayo 30 de 1994. Magistrado ponente: Dr. Eduardo Cifuentes Muñoz.

República de Colombia. Corte Constitucional. Sentencia T-737. Julio 14 de 2005. Magistrado ponente: Dr. Álvaro Tafur Galvis.

República de Colombia. Corte Constitucional. Sentencia T-406. Junio 17 de 1992. Magistrado ponente: Ciro Angarita Barón.

República de Colombia. Corte Constitucional. Sentencia T-428. Junio 24 de 1992. Magistrado ponente: Ciro Angarita Barón.

República de Colombia. Corte Constitucional. Sentencia T-547. Julio 1 de 2010. Magistrado ponente: Gabriel Eduardo Mendoza Martelo.

República de Colombia. Corte Constitucional. Sentencia T-652. Noviembre 10 de 1998. Magistrado ponente: Carlos Gaviria Díaz.

República de Colombia. Corte Constitucional. Sentencia T-745. Septiembre 14 de 2010. Magistrado ponente: Humberto Sierra Porto.

República de Colombia. Corte Constitucional. Sentencia T-1080. Diciembre 12 de 2012. Magistrado ponente: Jorge Pretelt Chaljub.

República de Colombia. Presidencia de la República. Decreto 330. (Febrero 8 de 2007). Por el cual se reglamentan las audiencias públicas ambientales y se deroga el Decreto 2762 de 2005. Diario Oficial 46.536. Bogotá, D. C.: Imprenta Nacional de Colombia.

República de Colombia. Presidencia de la República. Decreto 1320. (Julio 13 de 1998). Por el cual se reglamenta la consulta previa con las comunidades indígenas y negras para la explotación de los recursos naturales dentro de su territorio. Diario Oficial 43.340. Bogotá, D. C.: Imprenta Nacional de Colombia.

República de Colombia. Presidencia de la República. Decreto 2041. (Octubre 15 de 2014). Por el cual se reglamenta el Título VIII de la Ley 99 de 1993 sobre licencias ambientales. Diario Oficial 49.305. Bogotá, D. C.: Imprenta Nacional de Colombia. 
República de Colombia. Presidencia de la República. Decreto 3573. (Septiembre 27 de 2011). Por el cual se crea la Autoridad Nacional de Licencias Ambientales -ANLA- y se dictan otras disposiciones. Diario Oficial 48.205. Bogotá, D. C.: Imprenta Nacional de Colombia.

República de Colombia. Presidencia de la República. Decreto 4580. (Diciembre 7 de 2010). Por el cual se declara el estado de emergencia económica, social y ecológica por razón de grave calamidad pública. Diario Oficial 47.916. Bogotá, D. C.: Imprenta Nacional de Colombia.

República de Colombia. Presidencia de la República. Decreto 1953. (Octubre 7 de 2014). Por el cual se crea un régimen especial con el fin de poner en funcionamiento los Territorios Indigenas respecto de la administración de los sistemas propios de los pueblos indígenas hasta que el Congreso expida la ley de que trata el artículo 329 de la Constitución Política. Diario Oficial 49.297. Bogotá, D. C.: Imprenta Nacional de Colombia.

República de Colombia. Presidencia de la República. Decreto 2613. (Noviembre 20 de 2013). Por el cual se adopta el Protocolo de Coordinación Interinstitucional para la consulta previa. Diario Oficial 48.980. Bogotá, D. C.: Imprenta Nacional de Colombia.

República de Colombia. Presidencia de la República. Directiva Presidencial 10. (Noviembre 7 de 2013). Guia para la realización de Consulta Previa. Recuperado de: http://wsp.presidencia.gov.co/Normativa/Directivas/Documents/DIRECTIVA\%20PRESIDENCIAL\%20N\%C2\%B0\%2010\%20 DEL\%2007\%20DE\%20NOVIEMBRE\%202013.pdf

República de Ecuador. Corte Provincial de Justicia de Sucumbíos. Juicio No. 2011-0106. Martes 3 de enero de 2012. Juez Ponente: Milton Zeballos.

Reyes, A. (2009). Guerreros y campesinos, el despojo de la tierra. Bogotá, D.C.: Norma.

Romero, E. (2012). Desarrollo Sostenible hacia la Sostenibilidad Ambiental. Bogotá, D.C.: Produmedios.

Romero, E. (2013). En B. Marquardt, Constitucionalismo Científico, p. 303331. Bogotá, D.C: Temis.

Saint-Exupéry, A. (1994). El Principito. México D.F.: Enrique Sainz Editores.

Santos, B. (2003). Crítica de la razón indolente: contra el desperdicio de la experiencia. Bllbao: Desclée de Brouwer.

Shiva, V. (2001). El mundo en el límite. En A. Giddens, \& W. Hutton, El mundo en el límite, p. 163-186. Barcelona: Tusquets. 
Stern, N. (2007). Stern Review: La economía del cambio climático. Recuperado de: http://www.catedracambioclimatico.uji.es/docs/informestern.pdf

Stern, N. (2012). Puede ser más rentable dejar el petróleo bajo tierra. Semana. Recuperado de: http://www.semana.com/nacion/articulo/puede-mas-rentable-dejar-petroleo-bajo-tierra/266594-3

Tribunal de Ecuador ordena a Chevron solventar condena por daños ambientales. (2012, 5 de agosto). La Jornada. Recuperado de: http://www.jornada.unam.mx/2012/08/05/economia/023n2eco

Vargas, Y. (2014, 25 de septiembre de). La confusión conceptual del Director del ANLA: Sí son licencias exprés. El Espectador. recuperado de: http:// www.elespectador.com/noticias/medio-ambiente/no-un-proceso-expresarticulo-518743

Zaffaroni, E. (2011). La Pachamama y el humano. En A. Acosta, \& E. Martínez. La Naturaleza con derechos, de la filosofía a la política. Quito: Abya Yala. (25-138). 